Case Report

\title{
Variation in the area of distribution of the lateral pectoral nerve and a communicating branch between musculocutaneous and median nerve : A case report
}

\author{
Divia Paul A. ${ }^{1} \&$ Manisha Rajanand Gaikwad ${ }^{2}$ \\ 1 Junior Research Fellow, Department of Anatomy, Yenepoya M edical College, M angalore, Karnataka, \\ ${ }^{2}$ HOD, Department of Anatomy, All India Institute of M edical Sciences, Bhubaneswar - 751019, Odisha, India. \\ Correspondence \\ Divia Paul A. \\ Junior Research Fellow, Department of Anatomy, Yenepoya M edical College, \\ M angalore 575 018, Karnataka, India \\ Mobile : t91 7204215468 E-mail : divia manoj@yahoo.com
}

\begin{abstract}
Variations in the distribution of the lateral cord and its branches in the infraclavicular part of the brachial plexus are common and significant to the neurologists, surgeons, anaesthetists and the anatomists [1]. The present case describes a rare variation of the lateral pectoral nerve giving an additional branch to supply biceps brachii muscle and ends by joining inferior collateral branch of brachial artery. Also it was observed that the musculo cutaneous nerve received communicating branches from the median nerve before and after piercing the coracobrachialismuscle. The above observations were observed during routine dissection of a 55 year old Indian male cadaver. The musculocutaneous nerve, lateral pectoral nerve and its branches were identified and protected. The clinical importance of the variation is discussed.
\end{abstract}

Keywords : M usculocutaneous nerve (MCN), Lateral pectoral nerve (LPN), M edian nerve (MN), Communicating branches, Pectoralis Minor (PM).

\section{Introduction}

Brachial plexus variations are reported by various authors since it is common. A discussion of the anatomy of the brachial plexus is necessary in order to have a clear-cut idea to understand the deviation of plexus from normal explained in this case study. Complex nerve plexus which takes its origin from the neck and axilla which in turn formed by the union of the ventral rami of fifth to eighth cervical and the first thoracic spinal nerves is termed as brachial plexus. These fibres follow a complex pattern of uniting and dividing to form trunks, cords, the nerves of the upper extremities. Out of which the lateral and medial cord formation, branches is highlighted as in the present study

\begin{tabular}{|c|}
\hline Access this article online \\
\hline Quick Response Code \\
\hline
\end{tabular}
the branches of these cords are seen as communicating segments. Lateral cord contains the fibers from $\mathrm{C} 5, \mathrm{C} 6$ and $\mathrm{C} 7$, while the medial cord fibers are from $\mathrm{C} 8$ and $\mathrm{T} 1$. Normally, the lateral cord gives out lateral pectoral nerve for pectoralis major and minor muscle. Then it again divides into musculocutaneous and the lateral root of the median nerve. The musculocutaneous nerve $(C 5,6,7)$ after piercing the coracobrachialis muscle and supplies it. Passing downwards, following the lateral side of the arm between the biceps brachii and brachialis muscle the nerve supplies them also. The deep fascia is pierced, lateral to biceps brachii tendon by the nerve near elbow to continue downwards as lateral cutaneous nerve of the forearm. Segment that supply brachialis gives out a filament to the elbow joint. Twig to the bone, which enters the nutrient foramen is given by the nerve, that courses with the accompanying artery.

In relation to the antero-lateral part of third part of the axillary artery, median nerve (C5-T1) isformed by the union of medial and lateral root of median nerve from the medial cord and lateral cord of the brachial plexus. The course of median nerve is explained as first lateral to brachial artery and crosses in front the artery near coracobrachialis 
muscle insertion. It then descends medial to artery in the cubital fossa [2].

\section{Case report}

During routine dissection for the first year medical students of a 55 year old Indian male cadaver, in the Department of Anatomy, All India Institute of Medical Sciences, Bhubaneswar, Odisha the following variations were observed and noted.

Lateral pectoral nerve which usually supplies pectoralis minor and major was having an additional slender and long branch to supply biceps brachii muscle and ends by joining inferior collateral branch of brachial artery. Lateral pectoral branch to supply to pectoralis minor as well as major remained intact. (Fig no: 1) It was also observed that the musculocutaneous nerve received communicating branches from median nerve before and after piercing the coracobrachialis muscle. (Fig no: 2) Median nerve and musculocutaneous followed the routine course, lateral to the third part of axillary artery. Musculocutaneous nerve branches were given to coracobrachialis, biceps brachii and brachialis muscle as per the normal pattern of distribution. Median nerve was not having any other communicating branches to supply in the arm region and entered the cubital fossa medial to brachial artery and biceps tendon. The blood supply was confirmed from the branches of brachial artery.

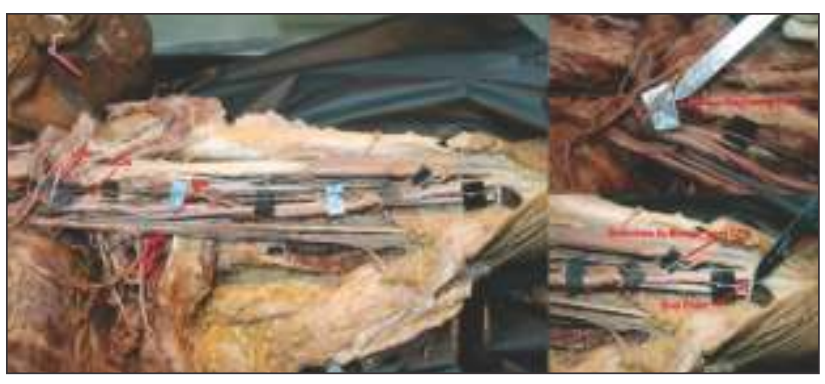

- LPN-Lateral Pectoral Nerve

- MCN-M usculocutaneous Nerve

- MN-M edian Nerve

\section{Discussion}

Venieratos and anagnostopoulou (1998) catagorised variations of communication between the $\mathrm{MCN}$ and $\mathrm{MN}$, in relation to coracobrachialis muscle among 79 cadavers.

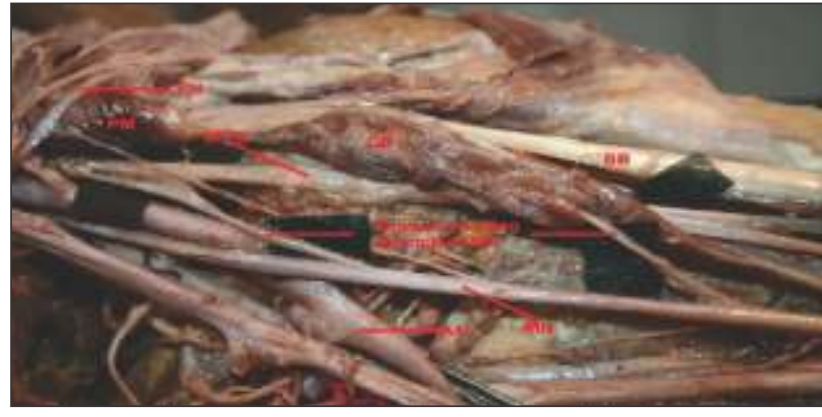

- LPN-Lateral Pectoral Nerve

- PM-Pectoralis M inor

- M CN-M usculocutaneous Nerve

- M N-Median Nerve

- CB-Coracobrachialis

- BB-Biceps Brachii

- AA-Axillary Artery

Proximal and distal in relation to the entrance of the musculocutaneous nerve into coracobrachialis as type I and type II. It is termed as Type III, if the nerve as well as the communicating branch did not pierce the muscle [3].

The present variation can be related to both type I and type Il variation of the above mentioned study.

Four different patterns of communication between median nerve and musculocutaneous nerve were observed by Loukas and Aqueelah (2005) among hundred and twenty nine, formalin-fixed cadavers. A communication is regarded as Type I (45\%, 54 communication,) if it is proximal to the point of entry of the MCN into the coracobrachialis; type II (35\%, 42 communications) were distal to the point of entry of the MCN into the coracobrachialis.Type III ( $9 \%, 11$ communications) were it is catagorised, if the M CN did not pierce the coracobrachialis. If type I alone with additional communication at distal end also it is classified as Type IV ( $8 \%, 9$ communications).

The present variation can be again related to both type IV classification of the above mentioned study.

Eglseder and Goldman (1997) noticed about 36\% of interconnections between the MCN and MN among 54 cadavers during discussion [5].Variants of branching pattern of MCN and MN have been a study criteria for many authors in 2002, namely Prasada Rao and Chaudhary who reported eight instances of communication from MCN to the MN and bilateral communication in two cadavers [6].Chauhan and Roy also reported unusual 
communication between the median and $\mathrm{MCN}$ in their case reports [7].

In contrast to this, Le M inor (1990) classified variations in communications between median nerve and musculocutaneous nerve to five types. If no communication between the $\mathrm{MN}$ and MCN as Type 1 and Type 2: If the fibers of medial root of $M N$ pass through the $\mathrm{MCN}$ and join the $\mathrm{MN}$ in the middle of the arm. Type 3 and Type 4 are in relation with fibers of the lateral root of the $M N$. If fibres pass through the MCN and after a distance leave it to form lateral root of $\mathrm{M} \mathrm{N}$ called type 3 and type 4 if the MCN fibers join the lateral root of the MN and after some distance the $\mathrm{MCN}$ arise from the M N. Type 5; If the $M C N$ is completely absent and the fibers of MCN pass through lateral root of $\mathrm{MN}$ entirely and direct branches are given out from $\mathrm{MN}$ to the fibers to the muscles supplied by MCN.MCN does not pierce the coracobrachialis muscle is not pierced by $\mathrm{MCN}$ in this classification [8].

Present finding does not indicated presence of Le M inor type variant.

No literature for a comparative study were obtained, on lateral pectoral nerve having an additional branch to supply biceps brachii muscle which ends by joining inferior collateral branch of brachial artery, unilaterally in the present study.

The existence of this variation described in our case report may be attributed, to the mechanism of formation of limb muscles and the peripheral nerves during embryonic life and the random factors influencing it. In the context that ontogeny recapitulates phylogeny; it is possible that the variation seen in the current study is the result of developmental anomaly. Five Hox D (Hox D 1 to Hox D 5) genes, regional expression is mainly responsible for upper limb development [9]. The motor axons arrive at the base of limb bud; which mix to form brachial plexus in upper limb. The growth cones of axons continue in the limb bud [10].The guidance of the developing axons in a highly coordinated sight specific fission, is regulated by the expression of chemo-attractants and chemo-repulsunt [11]. The tropic substances including brain-derived neurotropic growth factor, c-kit ligand, neutrin-1, neutrin2 , etc attract the correct growth cones or support the viability of the ingrowth cones that happen to take the right path. [12]. Altered signaling between mesenchymal cells and neuronal growth cones or circulatory factors at the time of fission of brachial plexus cords must have resulted in significant variations in nerve pattern.

\section{Morphological Importance}

The functional division of proximal lower limb in to adductor, flexor and extensor compartment is a clear cut demarcation. The nerve supply to these three compartments via obturator nerve (ventral division), femoral nerve (dorsal division) and tibial component of sciatic nerve (ventral division) maintain their source of origin. The fusion of adductor and ventral compartment of upper limb leads to the formation of two compartments of upper limb leading to wide variety of communication between these compartments. Both of which carrying the nerve supply from the ventral division of brachial plexus. M eanwhile, nerve supply to dorsal component maintain its identity without mixing with the anterior component because of two intermuscular septum (medial and lateral).

\section{Clinical Significance}

M eticulous knowledge of possible variations of $\mathrm{MCN}$ and the $\mathrm{MN}$ may endow valuable help in the management of traumatology of shoulder joint and arm as well as in circumventing iatrogenic damage during repair operations of these regions. Knowledge of brachial plexus variations has important anatomical and surgical clinical applications especially in relation to trauma and surgical procedures of upper limb $[13,14]$. The present case report provides additional knowledge on brachial plexus variations to clinicians, which may help to avoid damage during surgical procedures related to plastic and reconstructive surgeries. 


\section{References}

1. Gupta C D'Souza AS,Shetty P etal.A morphological study to note the anatomical variations in the branching pattern of the lateral cord of the brachial plexus.J ournal of M orphological Science. 2011; 28(3):0104.

2. Sakharam R.R,Mahadeo D.J,Sacchidanand J.S etal.Bilateral presence of third root of median nerve: a case report. Int J Anat Var (IJAV).2013; 6:74-76.

3. Venieratos D, Anagnostopoulou S.Classification of communications between the musculocutaneous and median nerves.Clin Anat. 1998; $11: 327-331$

4. Loukas M, Aqueelah H. Musculocutaneous and median nerve connections within, proximal and distal to the coracobrachialis muscle. Folia M orphol (Warsz). 2005; 64: 101-108.

5. Eglseder WA Jr, Goldman M. Anatomic variations of the musculocutaneous nerve in the arm. Am J Orthop (Belle Mead NJ). 1997; 26: 777-780

6. Prasada Rao PV, Chaudhary SC. Communication of the musculocutaneous nerve with the median nerve. East Afr M ed J. 2000; 77: 498-503.

7. Chauhan R, Roy TS. Communication between the median and musculocutaneous nerve - a case report. J AnatSoc India. 2002; 51: 72-75.

8. Le Minor JM. A rare variation of the median and musculocutaneous nerves in man. Arch AnatHistolEmbryol. 1990; 73: 33-42. (French)

9. Moore KL, Persaud TVN. Before we are born. 7th Ed. The musculoskeletal system. Philadelphia, Saunders Elsevier. 2003; 243-244.

10. Morgan BA, Tabin C. Hox genes and growth: early and late roles in limb bud morphogenesis. Dev Suppl. 1994: 181-186.

11. Sannes HD, Reh TA, Harris WA. Development of the nervous system: Axon growth and guidance. New York, Academic Press. 2000; 189- 197.

12. LarsonWJ.Human Embryology. Development of peripheral nervous system. 3rd Ed. Pennsylvania, Churchill Livingstone. 2001; 115-116.

13. Nakatani T, Mizukami S, Tanaka S. Three cases of the musculocutaneous nerve not perforating the coracobrachialis muscle.KaibogakuZasshi. 1997; 72: 191-194.

14. Aydinlioglu A, Cirak B, Akpinar F, Tosun N, Dogan A. Bilateral median nerve compression at the level of Struthers' ligament. Case report. J Neurosurg. 2000; 92: 693-696. 